\title{
ENTRE CADERNOS E PINCÉIS: A OBRA INACABADA NA EDUCAÇÃO DA PRINCESA “FLOR"
}

\section{- MARIA CELI CHAVES VASCONCELOS}

Universidade do Estado do Rio de Janeiro - Uerj/Proped

\section{ANA CRISTINA BORGES LÓPEZ MONTEIRO FRANCISCO}

Universidade Católica de Petrópolis - UCP

RESUMO O trabalho tem como foco recompor aspectos biográficos da princesa Maria Amélia, conhecida como a "princesa Flor", sobretudo, procurando analisar parte da esmerada educação que recebeu, tendo em vista o lugar presumível que ocupava naquele momento histórico, decorrente de seu parentesco muito próximo com o imperador do Brasil e com a rainha de Portugal, ambos seus meios -irmãos. Em um plano mais específico, são abordadas as cartas escritas pela princesa Maria Amélia para o irmão, Pedro II, nos anos de 1838 a 1853, que faziam parte de um programa de educação das crianças nobres, cuja "arte" epistolar era um dos conhecimentos a serem adquiridos, desde os primeiros ensinamentos. Os procedimentos metodológicos referem-se a um estudo baseado em fontes histórico-documentais e bibliográficas, com destaque para autores que já se debruçaram sobre a vida da princesa Maria Amélia, assim como jornais contemporâneos ao período estudado, especificamente, o Jornal 0 Panorama, publicado na cidade de Lisboa, no exemplar datado do ano de 1853. A princesa-Flor revelou uma excepcional formação, expondo nos salões europeus a educação esmerada que recebeu, enaltecida nos meios aristocráticos. Contudo, sua vida foi precocemente ceifada pela tuberculose, deixando profunda dor na duquesa de Leuchtenberg, assim como no irmão, que manteve com ela uma constante e fraterna correspondência.

Palavras-chave: Princesa Maria Amélia. Educação de crianças nobres. Cartas pessoais. Escritas intimas. Império do Brasil.

\section{ABSTRACT BETWEEN NOTEBOOKS AND BRUSHES:THE}

\section{UNFINISHED WORK IN THE EDUCATION OF PRINCESS "FLOWER"}

The work focuses on the biographical aspects of Princess Maria Amélia, known as the "Flower Princess", above all, trying to analyze 
part of the careful education that she received, considering the presumed place that occupied at that historical moment, due to her very close kinship with the emperor of Brazil and with the queen of Portugal, both his half-brothers. On a more specific level, the letters written by Princess Maria Amélia to her brother Pedro II in the years 1838 to 1853 are addressed, they were also part of a program for the education of noble children whose epistolary "art" was one of the knowledge to be acquired from the earliest teachings. The methodological procedures refer to a study based on historical-documental and bibliographical sources, with emphasis on authors who have already studied the life of Princess Maria Amélia, as well as contemporary newspapers for the period studied, specifically the $O$ Panorama newspaper, published in the city of Lisbon, in the 1853 copy. The Princess-Flower showed an exceptional formation, exposing in the European salons the careful education that received, extolled in the aristocratic means. However, his life was soon reaped by tuberculosis, leaving deep pain on the Duchess of Leuchtenberg, as well as on her brother, who maintained with her a constant and fraternal correspondence.

Keywords: Princess Maria Amélia. Education of noble children. Personal letters. Intimate writings. Empire of Brazil.

ENTRE CUADERNOS Y PINCELES: LA OBRA INACABADA EM LA EDUCACIÓN DE LA PRINCESA “FLOR"

El trabajo tiene como foco recomponer aspectos biográficos de la princesa María Amélia, conocida como la "princesa Flor", sobre todo, buscando analizar parte de la esmerada educación que recibió, teniendo en vista el lugar presumible que ocupaba en aquel momento histórico, derivado de su parentesco muy cercano con el emperador de Brasil y la reina de Portugal, tanto en sus medio hermanos. En un plano más específico se abordan las cartas escritas por la princesa María Amélia para el hermano Pedro II en los años 1838 a 1853, cuyo "arte" epistolar era uno de los conocimientos a ser adquiridos, desde las primeras enseñanzas. Los procedimientos metodológicos se refieren a un estudio basado en fuentes histórico-documentales y bibliográficas, con destaque para autores que ya se dedicaron a la vida de la princesa María Amélia, así como diarios contemporáneos al período estudiado, específicamente, el periódico o Panorama, publicado en la ciudad de Lisboa, de fecha copia del año 1853. La princesa-Flor reveló una excepcional formación, exponiendo en los salones europeos la educación esmerada que recibió, enaltecida en 
los medios aristocráticos. Sin embargo, su vida fue prematuramente ceifada por la tuberculosis, dejando profundo dolor en la duquesa de Leuchtenberg, así como en el hermano, que mantuvo con ella una constante y fraterna correspondencia.

Palabras clave: Princesa María Amélia. Educación de niños nobles. Cartas personales. Escrituras íntimas. Imperio de Brasil.

\section{Introdução}

Era sexta-feira, em plena primavera em Portugal, a princesa-menina debruça-se sobre a escrivaninha para escrever ao irmão, que estava no Brasil. Quantas coisas a menina gostaria de contar ao irmão um pouco mais velho? Talvez, falar sobre as suas últimas aventuras ou sobre as visitas que recebeu! Quais assuntos em comum teriam os irmãos de sete e treze anos, que valessem a pena registrar nas cartas que cruzariam o oceano? A cena, possivel de ser imaginada, tem ao centro a princesa-menina, entre cadernos e pincéis, contemplando o papel à sua frente, tamborilando a pena e cogitando as palavras endereçadas ao "querido mano".

A princesa-menina é Maria Amélia, única filha do segundo casamento de D. Pedro I, com a imperatriz Amélia de Leuchtenberg e que escreve para o irmão Pedro II, filho do primeiro casamento de seu pai com a imperatriz Leopoldina da Áustria. ${ }^{2} \mathrm{O}$ afeto cultivado entre os irmãos fora construído por meio dos esforços da imperatriz Amélia que, notadamente, nutria grande carinho pelos enteados, em especial,

1 A estação da primavera, em Portugal, tem início no dia 21 de março e vai até o dia 20 de junho. Normalmente, é uma estação do ano marcada por dias ensolarados, mais secos e com um aumento gradual das temperaturas.

2 Carolina Josefa Leopoldina Francisca Fernanda de Habsburgo-Lorena, nasceu em Viena, no dia 22 de janeiro de 1797 e faleceu no Rio de Janeiro, em 11 de dezembro de 1826. Era filha do imperador Francisco I da Áustria e de sua segunda esposa Maria Teresa da Sicília. Conhecida como Maria Leopoldina, foi a primeira esposa do imperador D. Pedro I e imperatriz consorte do Império do Brasil, de 1822 até sua morte. Foi, ainda que por pouco tempo (março e maio de 1826), Rainha Consorte do Reino de Portugal e Algarves. pelo menino que viria a se tornar o segundo imperador do Brasil. As vicissitudes na vida de Pedro I impuseram a Maria Amélia o seu nascimento e a sua infância em solo bem distante do Brasil e, por conseguinte, impossibilitaram que os irmãos se conhecessem. As aventuras, brincadeiras e sentimentos que, porventura, poderiam ter compartilhado, foram substituídos, tão somente, por uma intensa cordialidade entre os missivistas que jamais haviam se encontrado.

De Lisboa, a carta é escrita com bastante capricho, indicando que a caligrafia infantil começava a se firmar em letras bem desenhadas. À margem superior esquerda, observa-se o decalque de um ramo de flores, destacando a flor central, pintada de amarelo. Naquele final de semana, no dia 20 de abril de 1838, Maria Amélia escrevia ao irmão para lembrá-lo, não apenas da sua existência, mas dos laços de parentesco e amizade que deveriam unir a ambos.

Meu querido Mano Gosto tanto de escrever-te, ja que não te posso ver, que faço esta para dizer-te que he muito tua amiga tua Maninha.

Maria Amélia ${ }^{3}$

Essa e outras cartas de teor semelhante fazem parte do acervo "D. Maria Amélia", do Museu Imperial em Petrópolis, datadas dos anos de 1837 a 1853. Sem dúvida, da totalidade desse acervo, muitas cartas se perderam pelo caminho; nas prateleiras, gavetas, escani-

3 Carta de Maria Amélia para Pedro II, Lisboa, 20 de abril de 1838. Pasta D. Maria Amélia - LV - 1-02 - 1838. Museu Imperial/Ibram/MinC. 
nhos; escondidas, rasgadas, deixadas de lado, incineradas; ou até mesmo, nunca entregues, guardadas como relíquias, por alguém que as teve em mãos. Assim, essa correspondência mantida entre os irmãos, como tantas outras relações epistolares, guarda lacunas decorrentes das inúmeras circunstâncias que comprometem, sobremaneira, a memória de uma parte significativa da história do nosso país. Todavia, o que restou preservado das missivas trocadas entre a princesa e o seu parente mais próximo - e, também, o mais distante -, constitui-se em um significativo começo para se contar uma das possiveis tentativas mais esmeradas de se educar uma princesa.

0 presente trabalho tem como foco recompor aspectos biográficos da princesa Maria Amélia, conhecida como a "princesa Flor", sobretudo, procurando analisar parte da esmerada educação que recebeu, tendo em vista o lugar presumivel que ocupava naquele momento histórico, decorrente de seu parentesco muito próximo com o imperador do Brasil e com a rainha de Portugal, ambos seus meios-irmãos. Em um plano mais específico, são abordadas as cartas escritas pela princesa Maria Amélia para o irmão, Pedro II, nos anos de 1838 a 1853, uma vez que as mesmas não tinham apenas o propósito de estreitar laços de parentesco, demonstrar afeto, ou enviar notícias, mas, também, faziam parte de um programa pedagógico de educação das crianças nobres, cuja "arte" epistolar era um dos conhecimentos a serem adquiridos, desde os primeiros ensinamentos. Vale ressaltar que a análise das epístolas não desconsiderou a sua materialidade, em relação ao papel, tinta, símbolos gráficos, assim como a outros elementos que compõem o conjunto, buscando relacioná-los ao conteúdo da descrição do vivido.

Os procedimentos metodológicos referemse a um estudo qualitativo, baseado em fontes histórico-documentais e bibliográficas, com destaque para autores que já se debruçaram sobre a vida da princesa Maria Amélia, assim como jornais contemporâneos ao período estudado, especificamente o Jornal O Panorama que, segundo Silva (2014, p. 109), foi publicado na cidade de Lisboa, entre os anos de 1837 e 1868, fundado pela "Sociedade Propagadora de Conhecimentos Úteis", com o objetivo de democratizar a cultura. Contudo, o exemplar utilizado como fonte, neste artigo, data do ano de 1853, período em que $O$ Panorama não está mais sob a direção de Alexandre Herculano, seu primeiro redator, mas já é editado, provavelmente, por Luiz Augusto Rebelo da Silva, ${ }^{4}$ embora essa informação não esteja explícita no Jornal.

As fontes complementares compõem-se, ainda, dos egodocumentos selecionados, como cartas trocadas entre a família imperial, anotações e missivas da princesa Maria Amélia, com destaque para os documentos encontrados no Arquivo do Museu Imperial em Petrópolis, demonstrando a forma de pensar de uma princesa que, embora nunca tendo conhecido o irmão, exercia, por cartas, uma presença marcante no Império brasileiro.

\section{Mais do que uma noiva, uma mãe para os órfãos de São Cristóvão}

Abalado com a recente morte da imperatriz Leopoldina, D. Pedro I enfrentava, ainda, as agruras de um Brasil recém-independente. Em que pesem todos os problemas, 18 meses após sua viuvez, ele já começava a buscar uma nova consorte, ${ }^{5}$ encarregando para tal mis-

4 Para mais informações, ver: <http://hemerotecadigital.cm-lisboa.pt/FichasHistoricas/Panorama.pdf>. Acesso em: 27 mar. 2018.

5 Bragança (2009, p. 11) diz que "em suas horas de solidão, Dom Pedro havia individualizado através do Almanaque de Gotha, duas possiveis candidatas. No dia 20 de junho de 1827 envia duas cartas, de próprio punho, ao cunhado, o Arquiduque Francisco Carlos e ao Príncipe Carlos Teodoro da Baviera. Acompanhavam estas cartas duas procurações oficiais, munidas do selo imperial, a fim de serem procuradores num eventual casamento com as Princesas Luiza Guilher- 
são, o marquês de Barbacena, conhecedor dos atributos necessários ao futuro par. De acordo com Almeida (1973, p. 15), as tentativas malsucedidas nas Cortes europeias e o esfriamento de seu relacionamento com a marquesa de Santos acentuaram a urgência de encontrar uma nova imperatriz para o trono brasileiro. Sua má-fama acarretou oito recusas de possiveis sucessoras (MARIZ, 2016) e, por fim, só restou ao soberano rever suas instruções e informar ao marquês de Barbacena que:

o meu desejo, e grande fim, é obter uma princesa que por seu nascimento, formosura, virtude e instrução venha fazer minha felicidade e a do Império. Quando não seja possivel reunir as quatro condições, podereis admitir alguma diminuição na primeira e na quarta, contando que a segunda e a terceira sejam constantes. (DRUMMOND NETO, 2016, p. 306)

Consoante os esforços do visconde de Pedra Branca (ministro do Brasil em Paris), a escoIha recaiu sobre a filha do príncipe Eugenio de Beauharnais, a princesa Amélia de Leuchtenberg, ${ }^{6}$ com a condição de que a marquesa de Santos fosse afastada, definitivamente, do imperador e da Corte (AVELLA, 2014), cláusula indispensável a qualquer negociação.

Migrando de um país onde já havia, de certa forma, um maior desenvolvimento cultural, em relação às mulheres, Amélia de Leuchtenberg aportou no Brasil consciente do papel que deveria desempenhar como futura soberana. A exemplo de tantas outras princesas de diferentes casas dinásticas, partiu de sua terra natal

mina ou Maria Ana da Baviera. Supõe-se que estas procurações foram feitas arquivar por Metternich, não se encontrando alguma resposta".

6 A família Beauharnais Leuchtenberg surgiu na história europeia depois do Congresso de Viena. Eugênio, o filho adotivo de Napoleão, superou o fracasso napoleônico graças à acolhida do sogro, Maximiliano I da Baviera, que o estimava como um filho e que o investiu do antigo Ducado de Leuchtenberg, cuja família se havia extinguido. Grandes também eram os meios financeiros do novo Duque de Leuchtenberg, que adquiriu, posteriormente, do Governo da Baviera, o Principado de Eichstätt, que the proporcionou um assento na Câmara dos Príncipes Alemães. para um "mundo distante", a fim de se casar com um homem que só conhecera por meio de pinturas. Seus quase dezessete anos comportavam ainda uma missão maior: a responsabilidade de cinco enteados. Todavia, Amélia chegava para mudar, de uma vez por todas, a vida de D. Pedro I e da Corte brasileira. Baseado em uma "testemunha ocular" dos acontecimentos, Almeida (1973, p. 21-30) afirma que, no dia 16 de outubro de 1829, desembarcou na baía de Guanabara e foi recepcionada com muito entusiasmo pelo povo brasileiro e pelo "apaixonado marido". Assumiu o posto de personagem central das festas que se seguiram em louvor ao casamento real e avocou as honras de sua beleza, mencionada por muitos observadores do período, além de destacada por seus biógrafos, como detentora de um porte ereto, uma pele rosada, um busto avantajado que sustentava o rosto em formato de coração, olhos azuis, lábios carmim e bochechas vermelhas, emolduradas por cabelos de tons escuros.

Almeida (1973, p. 37) conta que a jovem imperatriz buscava desempenhar com maestria os seus deveres. Instaurou um protocolo na Corte; disciplinou o funcionamento do palácio, impondo horários a serem cumpridos; introduziu o refinamento dos serviços e da indumentária; impôs o francês como língua oficial da Corte; estabeleceu novas regras ao ordenar que, para falar com Pedro I, era necessário marcar antecipadamente uma audiência. Del Priore (2012) enfatiza, ainda, que "feminina, belíssima e moça, Amélia não só inspirou a Ordem da Rosa, condecoração criada pelo marido em sua homenagem, com a legenda 'Amor e Fidelidade', como consolidou nos trópicos um savoir-vivre característico das cortes europeias - algo que Leopoldina se esquecera de trazer na bagagem, com os livros de botânica e mineralogia" (DEL PRIORE, 2012, p. 245).

Mais importante, soube, sabiamente, conquistar seus enteados que passaram a chamá 
-la de "querida mamãe". Dedicou atenção aos filhos do marido, exercendo a figura materna que era esperada dela, embora ainda fosse muito jovem. Administrou e supervisionou o ensino que thes era dado para garantir que fosse oferecido o que havia de melhor possível, tomando como exemplo os moldes de outras crianças reais da Europa (SCHMIDT, 1927).

Não obstante, enquanto Amélia inaugurava suas funções como imperatriz, o imperador se incompatibilizava, cada vez mais, com a nação. A indenização paga ao reino de Portugal, em troca do reconhecimento da independência do Brasil, acarretou o sentimento no povo de que $D$. Pedro I estaria dividido entre sua pátria de nascimento e a sua de adoção. Além disso, a culpa pela morte da primeira imperatriz ainda the pesava na imaginação dos súditos (REZZUTTI, 2017). Tentando minimizar as discórdias políticas, o imperador acreditou que uma viagem pelas províncias, ao lado da nova consorte, restauraria sua reputação e acalmaria os ânimos. Como adverte Carvalho (2014), diferentemente do esperado por ele, foi recepcionado por uma população hostil, iniciandose uma série de revoltas, que o levariam a abdicar do trono em favor de seu filho de cinco anos. Amélia, por sua vez, imperatriz por tão pouco tempo, não teria o sossego do exílio. Ao contrário, outra luta aguardava D. Pedro em seu retorno à Europa, uma guerra de reconquista do trono de Portugal para a filha Maria da Glória, então usurpado por seu irmão Mi-

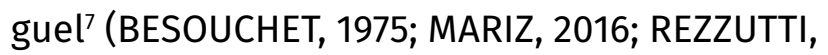
2017). Ao partir do Brasil, a imperatriz escreve para Pedro II o quanto lhe custava deixar órfãos, os filhos que ela tinha adotado:

Meu filho do coração e meu Imperador. Adeus, menino querido, delícia da minha alma, ale-

7 A Guerra Civil Portuguesa foi deflagrada porque o irmão de Pedro I, Miguel, tentou usurpar o trono português que à época pertencia à filha de Pedro I, Maria II. A guerra intensificou-se nos anos de 1833 e 1834, mas Pedro I (que era chamado de D. Pedro IV, em Portugal) derrotou seu irmão e restituiu o trono à filha. gria de meus olhos, filho que meu coração tinha adotado! Adeus para sempre! [...] Ah, querido menino, seu eu fosse tua verdadeira mãe, se meu ventre te tivesse concebido, nenhum poder valeria para me separar de ti, nenhuma força te arrancaria dos meus braços! [...] Mas tu, anjo de inocência, e de formosura, não me pertences senão pelo amor que dediquei a teu augusto pai. Adeus pois, para sempre! (ALMEIDA, 1973, p. 39-41)

Amélia partia do Brasil deixando para trás aquela criança ${ }^{8}$ em que todas as esperanças da nação estavam depositadas, tendo em vista a continuidade do Império, mas que para ela também era um pequeno menino a quem havia se afeiçoado. No entanto, já levava consigo uma nova vida.

\section{“Essa juventude tão ocupada em nobres tarefas, ficará como um modelo de educação de princesa" 9}

O nascimento de Maria Amélia, ${ }^{10}$ no dia 01 de dezembro de 1831, em Paris, foi anunciado como a vinda de uma "superbe petite fille"11 (ALMEIDA, 1973, p. 42) e ela foi presenteada pelos seus padrinhos de batismo, o rei da França Luís Filipe e a rainha Maria Amélia, com pulseiras de pérolas, nas quais estavam as miniaturas dos monarcas rodeadas de brilhantes (ALMEIDA, 1973, p. 44). No dia 04 de dezem-

8 No período da regência, Feijó convidou a ex-imperatriz Amélia para exercer as funções de preceptora e mestra de Pedro II e Francisca, filhos do primeiro casamento de seu marido, Pedro I. Mariz (2016, p. 18) conta que a iniciativa tinha cunho político, possivelmente já com vistas à implantação da República, mas as elites acabaram por derrubar Feijó, colocando no seu lugar o futuro marquês de Olinda, Araújo Lima. Este, por sua vez, acabou por reter as crianças no Brasil, chamando de volta a "Dadama" (condessa de Belmonte), para ser preceptora e aia dos dois jovens.

9 Frase de Almeida (1973, p. 91), ao tratar da educação da princesa Maria Amélia.

10 Era muito comum que a criança recebesse o nome da madrinha. Por isso, Maria Amélia recebeu esse nome não em homenagem à mãe, Amélia, e sim pela madrinha, a rainha da França Maria Amélia.

11 Linda garotinha. 
bro, Pedro I envia uma carta ao filho, Pedro II, anunciando o nascimento da irmã: ${ }^{2}$

\section{A.S.M.I. o Imperador do Brasil}

Meu Irmão e meu querido Filho. A divina Providência quiz aliviar a saudade que o meu coração paternal sente na separação de V.M.I., dandome mais huma Filha, e a V.M.I. mais uma irmãn e hum sudito, na Infanta do Brasil D. Maria Amélia que a Minha, sôbre todas presada Mulher, a Duquesa de Bragança, deu à luz no dia 1o do corrente Dezembro, com o mais feliz sucesso. Este dia de recordações gloriosas para a Nossa Augusta Família, assim na Europa, como no Brasil, e véspera de feliz natalício de V.M.I., parece ter sido escolhido pela Providência para reunir em um tão curto espaço, tantos objetos dignos de inspirar até as mais ternas emoções. Penetrado dos suaves sentimentos que elles lhe inspirarão. Cumpro com o dever sagrado de comunicar a V.M.I. aquele acontecimento; e acompanhando esta comunicação com a expressão sincera dos vivos desejos que Tenho de que o Céo encha de prosperidade a Pessoa e o Imperio de V.M.I., sou com o mais cordeal amor. Meu Irmão e mui querido Filho, De V.M.I. Afeiçoado Irmão e extremoso Pai. Paris, 4 de dezembro de 1831. (ALMEIDA, 1973, p. 42-43)

O júbilo pelo nascimento, tanto da família como dos súditos, fica aquém da tristeza que se constata, 21 anos depois, com a morte da princesa. De acordo com a matéria publicada no Jornal O Panorama, em 11 de junho de 1853, assinada pelo marquês de Rezende, ${ }^{13}$ antigo camarista de D. Pedro I e mordomo-mor da

12 A Princesa Dona Maria Amélia Augusta Eugenia Josephina Luiza Theodolinda Heloisa Xavier de Paula Michaela Gabriela Raphaela Gonzaga do Brasil nasceu em Paris, tendo sido a única filha do Imperador Dom Pedro I do Brasil (1798-1834) e da imperatriz Dona Amélia (1812-1873), nascida Princesa de Leuchtenberg.

13 Antônio Teles da Silva Caminha e Meneses foi o primeiro e único visconde com Grandeza e marquês de Rezende. Nasceu em Torres Vedras, em 22 de setembro de 1790, e morreu em Lisboa, em 08 de abril de 1875. Foi camarista de D. Pedro I e teve participação nas tratativas pós-independência do Brasil, passando a servir como embaixador em Viena, Paris e Moscou. Após a morte de D. Pedro, também atuou como mordomomor da ex-imperatriz Amélia, função que estava exercendo por ocasião da morte da princesa Maria Amélia. ex-imperatriz naquela altura, a "desgraça privada" descrita no artigo necrológico representava o sentimento de toda a população, "profundamente comovidos" com o "infortúnio" que, "nos corações portugueses, tomou a figura de uma calamidade pública" (1853, p. 186). Tratava-se da morte da princesa Maria Amélia ocorrida há alguns meses, em 04 de fevereiro de 1853. Iniciando a necrologia, o marquês lembrava que logo após o nascimento de sua filha caçula, D. Pedro partiu para a "ilha Terceira", onde estabeleceu uma regência para lutar pelo trono de Portugal, deixando a menina aos cuidados da imperatriz Amélia e na companhia da outra filha, Maria da Glória (Maria II), por quem estava sendo travada a guerra. Por quase dois anos, elas ficaram em Paris, retornando para Portugal, apenas, quando a guerra acabou e a coroa foi restituída a Maria II, aportando em Lisboa no dia 22 de setembro de 1833. No entanto, a convivência entre pai e filha durou pouco e, um ano depois, em 24 de setembro de 1834, D. Pedro morria de tuberculose no palácio de Queluz, onde nascera. A guerra trouxe a coroa usurpada para Pedro IV de Portugal (REZZUTTI, 2016), mas levou os primeiros anos de convívio com sua filha recém-nascida, além de legar a tuberculose que ceifou a sua vida, deixando Maria Amélia órfã de pai, aos 3 anos de idade e Amélia viúva, aos 22 anos. Sousa (2015, p. 1035) conta que:

[...] os tiros em funeral anunciaram [...] que o [...] Libertador já não existia. A 25 foi o seu cadáver autopsiado: Raro era o órgão indispensável à vida que não apresentasse lesões. 0 coração e o figado hipertrofiados. 0 pulmão esquerdo denegrido, friável, sem aparência vesicular quase todo, apenas numa pequena porção da parte superior era permeável ao ar. Os rins, onde fora encontrado um cálculo, inconsistente, esbranquiçados. 0 baço amolecido, a desfazer-se todo. (SOUSA, 2015, p. 1035)

A infância de Maria Amélia transcorreu como era o costume às crianças nobres, com 
toda etiqueta que a nobreza lhe impunha. Todavia, com a morte de D. Pedro, a ex-imperatriz passou a consagrar seus dias à educação da filha. Nas palavras de Almeida (1973, p. 56), “talvez já tivesse então concebido esse plano de educação ideal com que sonham todas as mães, e que ela soube realizar com perseverança sem precedentes, talvez por achar-se em posição tão eminente". Em um plano mais pragmático, é possivel que a educação esmerada proporcionada pela ex-imperatriz à filha visualizasse a possibilidade de sucessão, embora longinqua, em uma das casas reinantes herdeiras de seu pai, ou, mais provável, um casamento tão exímio quanto o seu, que a tornou de obscura princesa de um reino distante e parente de Napoleão, quando esse já era proscrito em grande parte da Europa, em imperatriz do novo mundo que, aos olhos dos monarcas ameaçados pelos ventos das deposições e constituições, parecia um lugar ainda propício ao absolutismo moderado.

A princesa menina, por sua vez, como sinaliza Almeida (1973), tinha sua inteligência e vivacidade reconhecidas por todos e se destacava por seu aprendizado precoce. Aos três anos, ela falava o francês, o português e o alemão correta e fluentemente. Conversava com as amas em português e em alemão. Com a mãe, que foi sua primeira mestra, segundo o marquês de Rezende (BRAGANÇA, 2009, p. 23), só falava em francês. De acordo com seus biógrafos, baseados em testemunhos da época, demonstrava uma impressionante capacidade de traduzir de uma língua para outra os trechos mais importantes dos grandes poetas e oradores e conseguia entender e estabelecer comparações entre diversas literaturas e características de cada nação. Amélia fazia questão de supervisionar pessoalmente a educação da filha.

A Rainha Carolina, juiz esclarecido e perito em educação, comprazia-se em conversar com a menina. Nada demonstrava, no entanto, que se quisesse apressar seu desenvolvimento intelectual. Somente, conhecendo-a melhor, se percebia, através de suas atitudes simples, ingênuas e despretensiosas, a retidão de idéias e o esmero com que the haviam dado noções nítidas, claras, precisas sobre todas as coisas. - Maria Amélia falava com facilidade o francês, o português e o alemão. Aprendera esses idiomas pela prática, sem esforço, sem sobrecarregar sua memória e falava essas línguas, sem misturá-las, como em geral fazem as crianças. (ALMEIDA, 1973, p. 58)

Embora educada por preceptoras, ${ }^{14}$ Maria Amélia não teve sua educação restrita às disciplinas que eram direcionadas para as mulheres. A princesa aprendeu piano ${ }^{15}$ (e o fazia com maestria), bordado, ${ }^{16}$ línguas, história, filosofia, ou seja, as disciplinas de ciências humanas voltadas à educação de princesas, mas também as disciplinas de ciências exatas que, por fim, acabaram conquistando sua preferência (ALMEIDA, 1973, p. 63-65; WITTE, 2013). A matemática e a fisica seduziram a jovem aprendiz e, aos 15 anos, ela opta por algo totalmente incomum para a época, indo fazer, de acordo com o artigo do Jornal o Panorama, o curso completo de "sciencias phyco-matthematicas", sob "a direção do doutor Sieber". Como não podia frequentar a Universidade, algo não admitido para as mulheres, recebia os estudos

14 De acordo com Vasconcelos (2005), as crianças nobres, particularmente as meninas, eram educadas na casa por meio da contratação de preceptoras, também chamadas de governantas ou aias. No caso de Maria Amélia, essa informação pode ser comprovada no Jornal O Panorama, na edição de 11/06/1853 (p. 186), quando é citada a "dama que a tinha educado".

15 Desde pequena, Maria Amélia demonstrou dom para a música. Almeida (1973, p. 55) relata que a princesa “ouvia-a atentamente, não com a alegria buliçosa, própria da sua idade, mas silenciosa e recolhida como quem compreende a linguagem dos sons".

16 Almeida (1973, p. 67) narra que as "artes ocuparam lugar preponderante nessa juventude vivida tão intensamente e foram o encanto da vida de Maria Amélia. A princesa desenhava e pintava com graça; tinha talento de primeira ordem para o piano, lia a música mais dificil à primeira vista e conhecia as regras da harmonia e da composição". 
na sua própria casa, mas, como registra o Jornal, "dando uma brilhante prova de seu aproveitamento n'este estudo em um exame que fez no gabinete de physica da Universidade de Munich, sendo, ao que cremos, a primeira pessoa da sua alta jerarchia e do seu sexo, que fez uma tão solene provança de sciencia" (O PANORAMA, 11/06/1853, p. 186).

Também demonstrava muito interesse pela astronomia e em suas viagens da Alemanha a Portugal, a bordo de um navio a vapor, costumava explanar seus conhecimentos topográficos e históricos, além de literários, deixando bastante impressionados os interlocutores em relação à grandiosa obra de educação que estava sendo preparada naquela princesa.

Almeida (1973) apresenta, ainda, a sua própria visão da educação de Maria Amélia, assinalando que o plano de estudos da princesa visava às faculdades, "evitando o desenvolvimento substancial da imaginação". Dessa forma, foi permitida a cultura das letras, desde que não "atingisse nem a serenidade do pensamento, nem a pureza do coração". Para tanto, "o romance fora banido" e para a leitura das obras-primas da literatura, fazia-se de antemão, uma seleção de trechos, "deixando para mais tarde o conhecimento do poema inteiro, quando, sem nada perder do encanto, já não apresentava perigo" (1973, p. 64).

Outra biógrafa de Amélia, Witte (2013, p. 45), sinaliza que "a educação de Maria Amélia era a preocupação fundamental da ex-imperatriz, que não media esforços para que a filha tivesse acesso aos melhores professores portugueses e bávaros". A princesa correspondia às expectativas da mãe e desde cedo se tornou exímia pianista, fluente em português, francês e alemão, chegando a estudar física e se formar no gabinete da Universidade de Munique, ${ }^{17}$ aos 19 anos (WITTE, 2013). Destarte os

17 A Ludwig-Maximilians-Universität München, também referida como LMU, foi criada em 1472. biógrafos, certo é que mãe e filha fizeram inúmeras viagens pelo continente europeu, a fim de que a educação da princesa fosse a mais esmerada e ampla possivel.

Almeida (1973) e Witte (2013) registram também que, concluindo a educação, era preciso pensar no casamento de Maria Amélia, que já poderia ocorrer a partir dos 18 anos. A princesa foi apresentada à Corte em Munique, no Natal de 1850, mas seu casamento deveria ser organizado em Portugal. A aliança havia sido feita há anos, numa reunião em família, em 1839. Desde os sete anos, Maria Amélia estava prometida a um primo, o arquiduque Maximiliano da Áustria..$^{18}$ Assim, quando o arquiduque fez uma viagem pela Itália, em 1852, estendeu-se até Portugal para conhecer a futura esposa.

Almeida (1973, p. 101-146) aborda a breve história de Maria Amélia e Maximiliano, narrando que assim que se conheceram, ${ }^{19}$ pois só haviam se encontrado quando crianças, apaixonaram-se imediatamente. Entretanto, Maria Amélia ainda não tinha se recuperado totalmente de uma recente escarlatina. Na verda-

18 Maximiliano da Áustria nasceu no castelo Schönbrunn, em Viena, no dia 6 de julho de 1832 (BRAGANÇA, 2012, p. 362). Filho de Francisco Carlos da Áustria que era irmão de Leopoldina, imperatriz do Brasil, primeira esposa de Pedro I. Portanto, Maximiliano era sobrinho de Leopoldina, primo dos irmãos da Maria Amélia. Por outro lado, também era primo da Maria Amélia, porque a mãe dele (Sofia) era meia-irmã da imperatriz Amélia.

19 No início de 1852, o arquiduque Maximiliano da Áustria, então servindo na marinha austríaca, visitou Amélia e Maria Amélia durante uma escala em Portugal (ALMEIDA, 1973, p. 111). A princesa já o conhecia de uma reunião familiar em Munique, em 1838. Sofia da Baviera, mãe de Maximiliano, era meia-irmã de Augusta Amália, a avó materna de Maria Amélia, e ambas pertenciam à Casa alemã de Wittelsbach (ALMEIDA, 1973, p. 57). O arquiduque também era primo dos meios-irmãos de Maria Amélia, visto que seu pai, o arquiduque Francisco Carlos, era irmão mais novo da imperatriz dona Leopoldina (ALMEIDA, 1973, p. 124). De acordo com Bragança, (2012, p. 363), ao ser condenado à morte, em 1867, Maximiliano entregou ao seu confessor um anel e uma medalha, que Maria Amélia havia the dado, para que fossem entregues à imperatriz Amélia do Brasil, mãe da jovem princesa já falecida. 
de, a doença havia evoluído para uma tuberculose e o noivado ocorreu de forma secreta, pois, embora debilitada, acreditavam na sua recuperação por ser jovem e forte. Outro motivo para que o noivado não fosse oficializado, era que o irmão de Maximiliano (imperador da Áustria) ainda não havia se casado. Como segundo filho, ele só poderia ficar noivo após o anúncio do casamento do irmão mais velho.

Registros encontrados nas cartas da princesa Maria Amélia endereçadas a Senhora Z., sua antiga ama e ao irmão, Pedro II, mostram que, em busca da cura, ela vai com a mãe para a Ilha da Madeira em 1852, para iniciar o tratamento da tuberculose. De lá, a correspondência com Pedro II continuou. As cartas do acervo “D. Maria Amélia”, do Museu Imperial, confirmam a permanente correspondência entre a princesa e o irmão, imperador do Brasil. No período analisado, não houve um aniversário sem que ela enviasse uma carta saudando o irmão e desejando votos de saúde e felicidade. Durante o período da enfermidade, ela também informava ao irmão sobre a evolução da doença e os tratamentos que buscavam. Na penúltima carta escrita antes da sua ida a Funchal, datada de 12 de abril de 1852, dá notícias de como a doença progredia entremeada a demonstração de seu regozijo em contar as novidades sobre as irmãs. Numa escrita pueril, ela mescla a satisfação de expor a visita das irmãs, numa tentativa de, talvez, minimizar o infortúnio da doença que a espreitava.

\section{Meu querido Mano Pedro}

É com muita pena que soube que tinhas estado doente, e bein do coração agradeço a Deus o teu restabelecimento. Acho galante o nós adoecer-mos no mesmo dia, tu com uma febre biliosa, eu com a escarlatina, e estou bem contente de tu não teres ficado tanto tempo de cama do que eu, pois só no 22 dia da escarlatina é que me levantei pela primeira vez; muito me aborreceu o estar sempre deitada sem poder ocupar-me de modo algum, porque, ainda algum tempo depois de estar já fora da cama, não me era permittido ler porque a molestia attaca muito os olhos, e é por esta razão que não te escrevi mais cedo. Agora estou outra vez boa, graças a Deus, só tenho ainda uma irritação na garganta, que soffreu bastante com a esquiscencia qui tive antes da escarlatina se declarar. Muito me alegro ver aqui a mana Januaria, que está agora com o marido em Londres, onde vio a Chica, que a achou mais gorda, na ultima carta da Januaria a Maman, dizia ella que não vinha, porque o mar a cançava muito, mas como a Mana Chica escreve que fazia tençãom demorar-se dous mezes na Inglaterra, espero que, achando-se então ja muito [...], assim mesmo não deixará passar a boa occazião de ver a Maman e a Mana Maria, que não vio há mais de 20 annos, e que Deus sabe quando puderá tornar a ver! ficaria eu tambem bem triste se não viesse, porque regozijo-me tanto de a ver! Vi o teu retrato que mandaste á Mana Maria, o que muito prazer me fez, vê-se que deve ser parecido. Ainda não recebi o que me prometteste na tua ultima carta, [...] estou com muita impaciencia de o receber. Muita pena me fez a morte do Marquez de Cantagallo, que éra tão amigo do Papa, e que tinha tanta amizade para nós todos que servia há tanto tempo; faz dó ver a Marqueza, que está tão afflicta, tão triste coetada! Adeus, meu querido Mano Pedro, não te escrevo mais por me faltar o tempo, mas peço te ficares bem lembrado desta tua Mana muito amiga Maria Amélia

P.S. Tenho agora a cabeça rapada porque perdia muito cabello desde as intermitentes, e o serei mais duas vezes para dar força ao cabello, acho isto mui commodo, sobre tudo com o calor e os banhos de mar, e espero deste modo ter cabello bom, d'aqui a 3 annos. ${ }^{20}$

Em que pese o otimismo registrado na carta, todos os esforços foram infrutíferos e a doença progrediu rapidamente. Maria Amélia morreu no dia 04 de fevereiro de 1853. Nas palavras de sua mãe, a imperatriz Amélia, Maria Amélia ascendeu aos céus aos 21 anos,

20 Carta de Maria Amélia para Pedro II. Lisboa, 12 de abril de 1852. LV 1-10 - 1852 - docs: 04. Museu Impe$\mathrm{rial} /$ Abram/MinC. 
dois meses e três dias de vida. Nas palavras de Almeida (1973, p. 51), "esta morte foi o término doloroso e sublime de uma educação esmerada - educação cristã na sua mais alta perfeição".

\section{A obra inacabada: uma curta existência, cercada de educação}

Embora os sentimentos relativos à morte, na primeira metade do oitocentos, não possam ser totalmente compreensíveis para os sujeitos da atualidade, de acordo com os testemunhos da época registrados no Jornal $O$ Panorama de 1853, a perda da filha foi para a ex-imperatriz Amélia algo semelhante ao que se pode considerar o conceito atual de ausência dos entes queridos. "Não se podem descrever tais sofrimentos: fica-se prostrado num silêncio respeitoso diante de tanta virtude e de tão justas lágrimas" (ALMEIDA, 1973, p. 85). Sem forças e coragem de sepultar a filha e tampouco voltar para Lisboa com a filha morta, Amélia manda embalsamar o corpo da princesa, envolve-o com muitas flores e permanece com ela, por dois meses, na capela do castelo em Funchal, na Ilha da Madeira. Somente em meados de 1853 é que Maria Amélia foi sepultada no panteão da família Bragança, em São Vicente, ao lado do pai, como era seu desejo.

De volta a Lisboa, Amélia passou a viver uma vida reclusa no Palácio das Janelas Verdes e dedicou o resto de seus dias à memória da filha. Inaugurou um hospital para o tratamento de pessoas carentes que se contaminavam com a tuberculose ("moléstias do peito"), com o nome de Hospício Maria Amélia. Empenhou grande parte da sua herança para o tratamento e a busca da cura da doença que levou seu marido, sua filha e alguns irmãos.

De 1853 até 1982, Maria Amélia ficou enterrada em Lisboa. Quando houve o traslado dos restos mortais da imperatriz Amélia para o Brasil, os da princesa Maria Amélia ${ }^{21}$ também vieram. Todavia, não foram sepultadas juntas. Enquanto Amélia foi sepultada no Ipiranga, em São Paulo, Maria Amélia foi levada para o atual Mausoléu Imperial,22 no Convento de Santo Antônio, no Rio de Janeiro (BRAGANÇA, 2009, p. 73).

As cartas trocadas entre os irmãos conservam-se como principais testemunhas de uma vida pensada, planejada e conduzida como uma obra educacional, quase à perfeição, para a época e para o que era permitido às mulheres daquela condição social. Nas saudações, novidades, felicitações e esperanças contidas nas cartas que cruzaram o oceano, como em um elo

21 O corpo da princesa permaneceu em uma capela ao lado da casa onde ela morreu, até ser levado de volta ao continente, 7 de maio de 1853 (ALMEIDA, 1973, p. 86). Em 12 de maio, o caixão foi desembarcado em Lisboa, seguindo-se um grandioso funeral (ALMEIDA, 1973, p. 88). Seus restos mortais foram enterrados ao lado dos de seu pai no Panteão dos Braganças, no Mosteiro de São Vicente de Fora (SCHIMIDT, 1927, p. 139; ALMEIDA, 1973, p. 89). Quase 130 anos depois, em 1982, o corpo de Maria Amélia foi trasladado para o Brasil, sendo definitivamente sepultado na cripta do Convento de Santo Antônio, no Rio de Janeiro, junto a outros membros da família imperial brasileira. "Na reunião da Comissão de Estudos e Pesquisas Históricas (CEPHAS), do Instituto Histórico e Geográfico Brasileiro, de 14 de abril de 1982, o então diretor do Museu Imperial de Petrópolis, Lourenço Luiz Lacombe, "[...] descreveu a cerimônia de entrega ao Brasil dos despojos de nossa segunda Imperatriz D. Amélia de Leuchtenberg (Duquesa de Bragança) e os de sua filha a princesa Maria Amélia. Informou o orador ter surpreendido grandemente a todos os que assistiram à abertura das urnas no Jazigo e Câmara Real do antigo Convento de São Vicente de Fora de Lisboa o fato de ainda estarem intactos, com excelente aparência, apesar do tempo decorrido desde o século passado, os corpos da segunda mulher e da filha do Imperador D. Pedro I". (Revista do Instituto Histórico e Geográfico Brasileiro, no 337, out-dez 1982, p. 270)

22 Ali encontraram abrigo os restos mortais da primeira imperatriz do Brasil D. Leopoldina, falecida em 1826 e sepultada no Convento da Ajuda, onde permaneceu até 1911. No Convento de Santo Antônio, ficaram seus restos até 1954, quando foram transladados para o Monumento do Ipiranga, em São Paulo. No Mausoléu estão sepultados D. João Carlos Borromeu e D. Paula Mariana, filhos de D. Pedro I e D. Leopoldina; D. Antônio Afonso e D. Afonso, filhos de Dom Pedro II e Dona Teresa Cristina; e Luísa Vitória filha da Princesa Isabel, que nasceu morta. Desde 1982, repousam também, vindos de Portugal, os restos mortais da princesa Dona Maria Amélia, filha de Pedro I e Dona Amélia Augusta. Disponivel em: <http://www.arqnet.pt/dicionario/mariaamelia2.html>. Acesso em: 14 mar. 2018. 
imaginário, Maria Amélia, certamente, influenciou o jovem imperador que, mais tarde, teria que pensar também a educação de suas duas filhas mulheres, princesas e com uma missão muito mais complexa, governar a nação. As lembranças da irmã, de sua educação tão esmerada podem tê-lo feito ampliar ou retardar a educação de suas próprias filhas. Quem sabe? Certo é que existiu entre os irmãos, por meio das cartas, palavras que aproximavam e traziam uma ilusão de intimidade àqueles que unidos pelo sangue, jamais se conheceram pessoalmente. Para além do irmão imperador, a obra inacabada realizada com tanto desvelo na educação da "princesa Flor", habitou a memória de todos aqueles que a conheceram e privaram da sua companhia entre livros, mapas, astrolábios, ábacos, cadernos e pincéis.

\section{Referências}

ALMEIDA, Sylvia Lacerda Martins de. Uma filha de D. Pedro I: Dona Maria Amélia. São Paulo: Companhia Editora Nacional, 1973.

AVELLA, Aniello Angelo. Teresa Cristina de Bourbon: uma imperatriz napolitana nos trópicos 1843-1889. Rio de Janeiro: EdUERJ, 2014.

BESOUCHET, Lídia. Exílio e morte do Imperador. Rio de Janeiro: Nova Fronteira, 1975.

BRAgAnÇA, Carlos Tasso de Saxe-Coburgo e. A Princesa Flor Dona Maria Amélia: a filha mais Linda de D. Pedro I do Brasil e IV do Nome de Portugal. Funchal: Região Autónoma da Madeira, Secretaria Regional de Educação e Cultura, 2009.

BRAGANÇA, Carlos Tasso de Saxe-Coburgo e. A intriga: retrospecto de intrincados acontecimentos históricos e suas consequências no Brasil Imperial. São Paulo: Editora Senac, 2012.

CARVALHO, José Murilo de. A construção da ordem. Teatro de sombras. A política imperial. Rio de Janeiro: Civilização Brasileira, 2014.

DEL PRIORE, Mary. A carne e o sangue: A imperatriz D. Leopoldina, D. Pedro I e Domitila, a marquesa de Santos. Rio de Janeiro: Rocco, 2012.
DICIONÁRIO HISTÓRICO. Dona Maria Amélia. Princesa do Brasil. Disponivel em: <http://www.arqnet.pt/dicionario/mariaamelia2.html>. Acesso em: 27 mar. 2018.

DRUMMOND NETO, Renato. Rainhas trágicas: quinze mulheres que moldaram o destino da Europa. Braga: Vogais com todas as letras, 2016.

JORNAL O PANORAMA. Sua Alteza Imperial a Princesa D. Maria Amélia. Lisboa, Vol. II, 3a série, edição de 11/06/1853, p. 185-192.

MARIZ, Vasco. Retratos do Império: os Orléans, os Saxe-Coburgo e outras personalidades da época. Rio de Janeiro: Topbooks, 2016.

REVISTA DO INSTITUTO HISTÓRICO E GEOGRÁFICO BRASILEIRO, no 337, out-dez 1982.

REZZUTTI, Paulo. D. Pedro IV - A história não contada. Portugal: Casa das Letras, 2016.

REZZUTTI, Paulo. D. Leopoldina: A história não contada: a mulher que arquitetou a independência do Brasil. Rio de Janeiro: Leya Brasil, 2017.

SANTUÁRIO E CONVENTO SANTO DE ANTÔNIO - Disponivel em: <http://www.webcitation.org/5x4kPWoR5>. Acesso em: 27 mar. 2018.

SCHMIDT, Maria Junqueira. Amélia de Leuchtenberg: a segunda imperatriz do Brasil. São Paulo: Companhia Melhoramentos de São Paulo, 1927.

SILVA, João Lourival da Rocha Oliveira e. O Panorama (1837-1844): Jornalismo e Ilustração em Portugal na Primeira Metade de Oitocentos. Covilhã: Livros Labcom Books, 2014.

SOUSA, Otávio Tarquínio de. A vida de Dom Pedro I (tomo 3o). In: História dos Fundadores do Império (Volume II). Brasília, DF: Senado Federal, Conselho Editorial, 2015.

VASCONCELOS, Maria Celi Chaves. A casa e os seus mestres. Rio de Janeiro: Gryphus, 2005.

WITTE, Cláudia Thomé. Amélia, a imperatriz de Luto. Revista História Viva, São Paulo, p. 40-45, abril de 2013.

Recebido em: 27.06.2018

Aprovado em: 20.08.2018 
Maria Celi Chaves Vasconcelos é Pós-Doutora em Educação pela Universidade do Minho. Doutora em Educação pela Pontifícia Universidade Católica do Rio de Janeiro - PUC-Rio. Mestre em Educação pela Universidade Federal do Rio de Janeiro - UFRJ. Professora Associada da Universidade do Estado do Rio de Janeiro (UERJ), atuando no Programa de PósGraduação em Educação (ProPed). Bolsista de Produtividade do CNPq desde 2011. Bolsista do Programa Prociência/Uerj desde 2015. Jovem Cientista da FAPERJ de 2012 a 2014. Cientista do Nosso Estado desde 2018. Membro do Conselho Estadual de Educação do Rio de Janeiro desde 2013. Presidente da Câmara Conjunta de Educação Profissional e Superior do Conselho Estadual de Educação desde 2016. Vice-Presidente eleita do Conselho Estadual de Educação para o período 2017-2019. Pesquisadora na área de História da Educação e Políticas Educacionais, com ênfase na educação doméstica no Brasil oitocentista e criação/consolidação dos sistemas educacionais, além da educação na casa (homeschooling) e suas implicações na atualidade. Líder do Grupo de Pesquisa História e memória das políticas educacionais no território fluminense (Uerj/CNPq) e vice-líder do Grupo de Pesquisa Interinstitucional Educação de Mulheres no Brasil nos séculos XIX e XX). e-mail: maria2.celi@gmail.com

Endereço: Rua Fonte da Saudade, n. 240, apto. 501, Lagoa, Rio de Janeiro, Brasil, CEP: 22471-210. Telefone: +5521982089972

Ana Cristina Borges López Monteiro Francisco é Doutora em Educação pela Universidade Católica de Petrópolis. Mestre em Educação pela Universidade Católica de Petrópolis. Curadora da Exposição "Condessa de Barral: cartas e imagens" e Pesquisadora de temas relacionados à educação de mulheres nobres no Brasil do oitocentos. No magistério há mais de vinte anos, integra o Grupo de Pesquisa História e memória das políticas educacionais no território fluminense, e o Grupo de Pesquisa Interinstitucional Educação de Mulheres no Brasil nos séculos XIX e XX. Conciliadora do Juizado Especial Criminal, nomeada pelo Tribunal de Justiça do Rio de Janeiro (1998/2000). Coordenadora do Núcleo de Prática Jurídica da Fundação Educacional Serra dos Órgãos (2003/2005). Membro das Comissões de Ensino Jurídico - Ordem dos Advogados do Brasil/RJ (2005/2006) e de Estágio (2009). Possui experiência na área de Direito (desde 1998), com ênfase em Direito Penal, Processo Penal, Criminologia, Pesquisa Jurídica. Linhas de pesquisa: Direito Penal, História do Direito, Direito Educacional, Ensino Jurídico. e-mail: acf@monteirofrancisco.com.br

Endereço: Avenida Portugal, n. 233, Bloco 1, apto. 301, Valparaíso, Petrópolis, Rio de Janeiro, Brasil, CEP: 25655-374. Telefone +5524981262626 